\title{
Erratum to: Screening and characterization of a non-insecticidal Bacillus thuringiensis strain producing parasporal protein with selective toxicity against human colon cancer cell lines
}

\author{
Periyasamy Abirami ${ }^{1}$ - Kkani Poornima ${ }^{2}$. Chandrasekaran Binuramesh ${ }^{2}$. \\ Ponnusamy Suguna $^{1}$ - Viswanathan Saranya ${ }^{1}$. Selvanayagam Peter ${ }^{1}$. \\ Rajaiah Shenbagarathai ${ }^{1}$
}

Published online: 8 March 2016

(C) Springer-Verlag Berlin Heidelberg and the University of Milan 2016

Erratum to: Ann Microbiol

DOI 10.1007/s13213-016-1204-8

The original version of this article unfortunately contained mistakes. The names of all authors are inadvertently inverted and are now corrected in the authorgroup of this article.

The online version of the original article can be found at http://dx.doi.org/ 10.1007/s13213-016-1204-8.

Rajaiah Shenbagarathai

shenbagarathai@rediffmail.com

Periyasamy Abirami

get2abirami@gmail.com

Kkani Poornima

poornimakkani@gmail.com

Chandrasekaran Binuramesh

binuramesh@yahoo.com

Ponnusamy Suguna

suguna.bt@gmail.com

Viswanathan Saranya

biovsa16@gmail.com

Selvanayagam Peter

selvanayagampeter@yahoo.com

1 PG and Research Department of Zoology and Biotechnology, Lady Doak College, Tallakulam, Madurai 625002, Tamil Nadu, India

2 PG and Research Department of Zoology and Microbiology,

Thiagarajar College, Madurai 625009, Tamil Nadu, India 